From human-nature to cultureplace in education via an exploration of unity and relation in the work of Peirce and Dewey

Corresponding Author:

Dr John Quay

Melbourne Graduate School of Education

The University of Melbourne

Level 3, 234 Queensberry Street

The University of Melbourne

Victoria 3010

Australia

+61383448533

jquay@unimelb.edu.au

John Quay is a senior lecturer in the Graduate School of Education at The University of Melbourne.

\title{
Acknowledgments
}

Many thanks to Martin Lindner, Martin Vollmar, Peter Becker, Ralf Westphal, Teresa Segbers, Jan Wypich, Kirsti Pedersen-Gurholt and Chris Loynes whose association through the Transcultural European Outdoor Studies program enabled me to visit the University of Marburg and to participate in numerous discussions of Welsch's work and the broader issue of transculturality which have significantly contributed to this paper. Many thanks also to the anonymous reviewers whose comments have helped improve this paper markedly.

\section{From human-nature to cultureplace in education via an exploration of unity and relation in the work of Peirce and Dewey}

\begin{abstract}
In outdoor education discourse the notion of relation is often employed to convey basic connections between humanity and nature as human-nature relationships, yet the sense of relation itself is rarely questioned. Drawing on the work of Peirce and Dewey, I explore the ramifications of a more nuanced understanding of relation, specifically how relation works with and within differing senses of unity. These ramifications have consequences for how we understand human-nature relationships, which I argue are better conveyed in terms of culture-place. The various forms of unity described by Peirce inform more nuanced understandings of culture-place as cultureplace, with implications for the notion of transculturality. My specific concern with outdoor education then enables me to show how cultureplace and culture-place may be considered to have relevance pedagogically, especially in relation to dealing with cultural and environmental crises.
\end{abstract}

Keywords: culture; place; relation; unity; Peirce; outdoor education; transculturality 


\section{The issue of relation and unity: Peirce's three forms of unity}

In this paper I aim to contribute to the "sorts of in-depth discussions of education in relationship to cultures in local and global places which provide critical direction" (McKenzie 2008, p. 361) - critical direction towards understanding and working through environmental and cultural crises. As McKenzie alludes, central to these discussions is how we understand relations between cultures and places, and how we may work with these understandings educationally; so "the point is not what we call what we do, but how we understand and practise it" (p. 369). These in-depth discussions must draw theory and practice together in order to develop educational ways through the myriad of serious cultural and environmental crises we are facing today. My contention is that cultural crises and environmental crises can be considered as one and the same, drawing culture and place together as a unity. Yet in order to comprehend this more adequately, and how such comprehension may inform educational discussions, the notion of unity must be explored, an exploration which cannot ignore the notion of relation.

My educational focus is specifically on outdoor education as a practice, as I suggest that outdoor education draws culture and place together educationally, but not as a discipline like geography, where they exist to be studied. In outdoor education culture and place are experienced, they are encountered in a living unity (Waite, 2013; Wattchow \& Brown, 2011). ${ }^{1}$ This is not to say that in geography classes culture and place are not 'there' in the living situation, they are just not attended to in this way in geography. In geography they are primarily dealt with as concepts to be investigated and defined (usually in connection with situations other than that of the geography classroom) for purposes of learning commonly driven by assessment. In outdoor education, by contrast, learning occurs more directly through living, in a way similar to that which Dewey argued for when speaking of "the ideal school": "Learning? certainly, but living primarily, and learning through and in relation to this living" (1900, p. 53). Hence learning that occurs through outdoor education does not merely concern the acquisition of various pieces of knowledge for assessment purposes (often justified on the basis that this knowledge may then be useful in some yet to be experienced future). There is a discernable relation between culture and place when they are emphasized as concepts, however this form of relation is different that experienced in outdoor education, where learning occurs through living and is primarily relevant to that present mode of living.

Such learning through living is today often referred to as experiential (Quay, 2003; Quay and Seaman, 2016), drawing on the work of Dewey again, who contended that "'life' covers customs, institutions, beliefs, victories and defeats, recreations and occupations"; and "we employ the word 'experience' in the same pregnant sense" (1916, p. 2). However, while Dewey acknowledged connections between learning and life/experience, he distinguished these from education per se, noting that "experience and education cannot be directly equated to each other" because "some experiences are mis-educative" (1938, p. 25). In other words, the learning accruing to some life experiences may not be deemed positive in light of "the growth of further experiences" (p. 25). This does not preclude an equation between learning and life, but between learning and education. This distinction will be reflected upon in the final stages of this paper in relation to education's contribution to cultural and 
environmental crises.

My basic philosophical argument in this paper is that our understandings of living/experiencing are impacted by the various ways in which we understand the notion of relation, a notion which is itself underpinned by varying senses of the notion of unity. Dewey claimed that "all philosophy is a search for unity, or, if this cannot be found, for unities; and it is the nature and quality ascribed to unity or unities, together with the reasons given for selecting it as such, that constitute the true philosophic history of the term" (1902, p. 736). This paper expresses an investigation of unity, through the process of which I also enlist the support of Peirce (1902) who, like Dewey above, contributed to the definition of 'unity' in Baldwin's Dictionary of Philosophy and Psychology. Peirce suggests three forms of unity aligned with different conceptions of the number one (which is the Latin root for unity). I detail these here because they will support exploration of other ways in which to understand the notion of relation and thus contribute to different understandings of living/experiencing which underpin how we may consider culture and place.

The first form of unity Peirce calls "simplicity"; here consideration of the number one is undertaken "irrespective of the possibility of two, three, \&c., [and thus] it involves no idea of number (and therefore not of totality or collection), nor even any idea of relation" (1902, p. 734). Please note here the absence of relation in this understanding of unity. This simple unity is such that the whole is primary - to the extent that no distinctions are made with-in it or with-out it; so there are no distinct parts that can be in a relation and, there is no cognizance that this unity is one whole amongst other wholes - there are no boundaries here. "The idea would, therefore, be found in a pure state only in an immediate consciousness which should make no distinction of any kind, whether between subject and object, or of the parts of the object" (p. 734). Peirce's reference to 'immediate consciousness' raises the issue of time, suggesting similarity with "the instant field of the present" which James (1912, p. 23) called "the 'pure' experience." Dewey also made reference to pure experience, offering a further contribution to its understanding by calling it aesthetic experience.

[A] esthetic experience is experience in its integrity. Had not the term "pure" been so often abused in philosophic literature, had it not been so often employed to suggest that there is something alloyed, impure, in the very nature of experience and to denote something beyond experience, we might say that [a]esthetic experience is pure experience. For it is experience freed from the forces that impede and confuse its development as experience; freed, that is, from factors that subordinate an experience as it is directly had to something beyond itself. (Dewey 1934 p. 274)

Here aesthetic does not so much refer to beauty but to perception (which is the Greek root for aesthetic). Peirce's first form of unity thus suggests the simplicity of a pure perceptual experience, directly had in the present. In further description of aesthetic experience, Dewey went on to say that "all the elements of our being that are displayed in special emphases and partial realizations in other experiences are merged in [a] esthetic experience" (1934 p. 274). "And they are so completely merged in the immediate wholeness of the experience that each is submerged: it does not present itself in consciousness as a distinct element" (p. 274). Culture and place could be said to characterize this pure experience, but they are 'submerged' in this form of unity. 
This experiential understanding of Peirce's first form of unity is critical to how we comprehend his second form of unity which, he says, is "very appropriately termed individuality"; it is "the oneness element of experience which involves a positive assignment of the number one, and which must be originally one, and not a total" (1902, p. 734) (the sense of a totality is in the third form of unity). Again Peirce invokes experience in his descriptions of unity. Individuality here does not refer to an individual entity as such but to the individuality, peculiarity, uniqueness of direct experience - what Thayer-Bacon (2003) refers to as the "thatness of experience" (p. 155). This second form of unity raises to awareness the notion that this direct experience is positively 'one' and no longer 'pure.' Direct experience, what Dewey has described as "transaction" $(1938$, p. 43) or "the fact that we are forced to react and that things react upon us in return for our reaction to them" $(1937$, p. 416) is commonly considered to involve two entities, but the experience itself is, in this form of unity: one. "Much may be said for the opinion that we are thus brought to the event of acting and being acted upon; for that must be one," Peirce (1902, p. 734) insists, "and is the only element of experience whose essential peculiarity is entirely lost in any generalization of it." In this form of unity, culture and place together as one - as cultureplace - may, I shall argue, be used to describe this direct experience in its uniqueness, its individuality, as one, as whole.

So in this second form of unity we make a distinction that enables us to say 'one'. Still, in this second form of unity the whole is primary and there are no distinctions made within it; it is one whole amongst other possible wholes. Perceived relations are between wholes. Very importantly, this sense of unity is not directly tied to contemporary psychological or sociological conceptions of individuality, where individuality often has more to do with unrelatedness. In contrast, the meaning of individuality as unity stems from the Latin root which denotes indivisibility. There is a notion of possible relation embedded here - between indivisible ones - but the primary factor is the indivisible whole. How we understand unity as individuality, as indivisibility, is central to the argument I am mounting in this chapter.

Peirce's third form of unity is "synthetical unity" which is more commonly known as "totality or universality"; this is "the idea which the word unity is usually employed in philosophy to express[:] ... that of a general (in the most general sense) in its relation to particulars" (1902, p. 734). This third form of unity is the one we are most familiar with; and it is internally relational. The direct experience is here understood by way of transaction, with the focus on the relations between specific entities involved in a transaction rather than on the positive oneness of the direct experience. Here the experiential whole is a total, a sum, comprised of many parts in relation. Our contemporary understanding of nature experienced as ecosystem is one such synthetical unity - a totality: a total whole of relations between things. We often consider the universe in this way - as the sum total of many parts in relation. In this synthetical unity, culture and place are related parts within a wider whole, which is consistent with the way we consider them in disciplines such as geography.

It is important to state here, at the outset, that I am not suggesting one form of unity as necessarily better than the others in some form of competition. Rather, it is an awareness of different forms of unity that I am highlighting via Peirce's work, and the possibilities that this awareness offers us for a better understanding of the unity of 
place and culture. In addition to the work of Peirce, I am supported by the philosophy of Dewey in making many of the points relevant to my argument throughout the remainder of this paper. May I foreshadow that central to this argument, getting back to the notions of culture and place, is engagement with the idea of transculturality as introduced by the sociologist Welsch.

\section{From human-nature to culture-place}

One way in which experiential unity is commonly expressed, especially in discourses associated with outdoor education, is through the notion of human-nature relationships, where humans and nature are inter-acting (see for example Martin and Thomas 2000; Martin 2004). I have deliberately hyphenated this term to draw attention to the sense that there are two 'things' (which can be concepts/ideas as well as concrete physical things) involved here in some form of relation - an understanding which fits neatly with Peirce's third form of unity, as synthetical unity. Thinking of life in terms of human-nature relationships positions humans as entities related to a myriad of other entities which are themselves related as "non-human nature" (Martin, p. 22). These relationships are generally comprehended ecologically, scientifically, by including humans within nature as genus and species (homo sapiens) and as part of the ecosystem. The overarching view is of a total system of relations between a vast collection of things (nature), some of which are human beings. In a positive way the notion of human-nature relationships overcomes the dualistic representation of humans and nature, enabling a synthesis (Peirce's third form of unity) to be achieved - which we label inclusively as nature.

There is an important difference, however, between this sense of human-nature relationships and that conveyed by the relations of culture-place. This difference is well illustrated in a paper titled Indigenous Perceptions of the Human-Nature Relationship (Salmón 2000) which describes human-nature relationships in a traditional indigenous way of life, by detailing what I consider to be more accurately described as culture-place relationships. I am drawing on an indigenous perspective to highlight a different form of synthetical unity than that usually embraced by western science. This different synthetical unity is dominated by the social character of relations rather than considering the synthesis to be primarily physical; perhaps prioritizing cultural synthesis over physical or natural synthesis. Thayer-Bacon comments that "for Native Americans, the world in which we live is considered alive, and we are intimately part of this life. They do not view themselves as autonomous, separate individuals in the traditional Euro-western classical liberal sense, but rather have contextual, communal views of themselves as individuals-in-relation-withothers" (2003, p. 168), where the others can be non-humans.

Through descriptions of his own "culture, the Rarámuri" of the eastern Sierra Madres of Chihuahua in Mexico, Salmón (2000, p. 1327) gives voice to cultural practices in his "homeland" which articulate the "human-nature relationship." In so doing, he expresses human-nature relationships in a local and practical way, arguing that these "cultural practices of living with a place ... are manifestations of kincentric ecology"; where kincentric ecology is "an indigenous perception of ecology" (p. 1332). I argue that this indigenous perception of ecology as kincentric ecology suggests a way of seeing human-nature relationships as culture-place relationships. 
Kincentric ecology pertains to the manner in which indigenous people view themselves as part of an extended ecological family that shares ancestry and origins. It is an awareness that life in any environment is viable only when humans view the life surrounding them as kin. The kin, or relatives, include all the natural elements of an ecosystem. Indigenous people are affected by and, in turn, affect the life around them. (Salmón 2000, p. 1332)

Kincentric ecology offers an indigenous perspective on ecological understanding wherein human-nature relationships are characterized as "kindred relations" (Salmón 2000, p. 1331). These do not emphasize ecosystemic relations in a scientific sense, but are more fittingly described, I suggest, as relations of culture-place. Human beings are not only physical/biological, but also social/cultural. Nature is not just a vast ecosystem, it is place, where emplaced nature is known via social/cultural meanings. Thus life is not merely eco-systemic in the sense of a physical universe. It can also be construed as specific cultural practices entwined with the particular rhythms of a place, where 'rhythm' derives from Dewey's observation that "unless nature had regular habits, persistent ways, so compacted that they time, measure and give rhythm and recurrence to transitive flux, [then] meanings, recognizable characters, could not be." (1929, p. 285).

The idea of culture-place relationships offers a subtle but significant shift away from an ecosystemic conception of relation - wherein being human is to be part of the larger ecosystem - to one which emphasizes the "cultural practices of living with a place" (Salmón 2000, p. 1332).

In this differing sense of synthetic relation (different to human-nature relationships), what were physical causes and their effects - otherwise understood as physical versions of "universal if-then propositions" (Dewey 1936, p. 673) - are now relations of "means and consequences" (Dewey 1938, p. 84) in a social world qualified as culture-place. ${ }^{2}$ Hence "a [physical] relationship of cause-effect has been transformed into [a social] one of means-consequence" (Dewey 1929, p. 300). In short, the physical if-then relations of cause-effect are now socially constituted, in a particular culture-place, as means-consequence relations.

Although we have to act in order to discover the conditions underlying the "if " in physical matters, yet the material constituting the "if" is there apart from our action; like the movements of the sun and earth in an eclipse. But in social phenomena the relation is: "If we do something, something else will happen." The objective material constituting the "if" belongs to us. We are concerned not with a bare relation of cause and effect, but with one of means and consequences, that is, of causes deliberately used for the sake of producing certain effects. (Dewey 1931, p. 277)

Understanding cause-effect as means-consequence is a matter of meaning making and thus of intelligence. Dewey argues that "all the intelligent activities of men [sic], no matter whether expressed in science, fine arts, or social relationships, have for their task the conversion of causal bonds, relations of succession, into a connection of means-consequence, into meanings" (1929, p. 299). In other words, "things gain meaning when they are used as means to bring about consequences (or as means to prevent the occurrences of undesired consequences), or as standing for consequences 
for which we have to discover means" (1933, p. 146). Dewey therefore regards "the relation of means-consequence" to be "the center and heart of all understanding" ( $\mathrm{p}$. 146). But importantly this understanding is not somehow a human thing that can be disconnected from the physical world. Dewey acknowledges that "apart from relations of cause and effect in nature, conception and invention could not be" (1934, p. 25). This points to the contextual character of means-consequence relations, situated in a culture-place.

The broader significance of the socialization or enculturation of cause-effect relations as means-consequence relations does not escape Dewey. He believes that with such an understanding "the supposed grounds for opposing human experience to the reality of nature disappear" (1929, p. 234). So while human beings are physical entities, they cannot be fully understood in this way. "Experience" is more than simply physical existence, for it involves "a transformation of interaction into participation and communication" (1934, p. 22). There is much going on here, and yet a comprehensive explanation does not seem to be achievable through western scientific understandings of ecosystemic relations alone. The distinction between human-nature and cultureplace hints at something different.

\section{From culture-place to cultureplace}

Of course, like human-nature relations, we can inspect means-consequence relations in their contribution to a synthetical unity. However means-consequence relations can also be "submerged" (Dewey 1934, p. 274) within the individuality, uniqueness, peculiarity of $a$ cultureplace (note removal of hyphen). Unified holistically, indivisibly, as Peirce's second form of unity, cultureplace is different from cultureplace. A cultureplace can be perceived as an indivisible unity amongst other cultureplace unities (one amongst other ones). In other words there is more than one possible cultureplace unity and relations can occur between these unities. Salmón's cultureplace, his homeland (note no hyphen), is one possible cultureplace, but there are others. And taking into consideration Peirce's first form of unity, we can account for life in cultureplace being ordinarily lived in routine simplicity - meaning that everything makes sense within this unity, this whole, such that it is unquestioned (this is not meant to emphasize a primitive simplicity but a simplicity experienced by all in daily living). Considering cultureplace in Peirce's second form of unity enables this cultureplace to be questioned amongst other cultureplace unities. Further consideration of a cultureplace as culture-place (a synthetical unity) opens up the possibility for questioning the internal means-consequence relations.

These shifts between Peirce's three forms of unity are subtle but significant. In one direction it is a shift from a very general culture-place or human-nature unity (third form), to a more particular holistic cultureplace unity (second form), to the sense of this unity being lived in an unquestioned manner (first form). In the other direction, this simple lived (first form) unity can be regarded as one cultureplace unity amongst others (second form), as well as a synthetical unity (third form) of culture-place relations understood as means-consequence relations (or more broadly, as humannature relations understood as cause-effect relations) that embrace one or more or all cultureplace unities. 
Making these moves reveals differences between human-nature, culture-place and cultureplace in terms of relation. If we think of culture-place, rather than humannature, it is more difficult to think biologically, ecosystemically. Culture-place says more than this. And while they can be construed as related and inter-acting like human-nature - culture with place, place with culture - they can also be understood as indivisibly unified and lived as simple whole, as cultureplace, in that place is always already encultured, and culture is always already emplaced. ${ }^{3}$

\section{Transculturality: repositioning culture as nature}

Salmón's (2000) description of the cultural practices of his homeland highlights a sense of originality and individuality: living for many generations and seasons with minimal change. Indeed, historically, there are examples of cultureplace where people have lived in the same place over long periods of time and in relative isolation from others - whilst maintaining cultural practices that have changed little, apart from seasonal adaptations to the regular rhythms of nature. ${ }^{4}$ Such examples of cultureplaces seem to represent ideal versions of Peirce's second form of unity - as individual experiential wholes. However the increasingly rapid pace of globalization has rendered such cultureplace isolation a rarity, if not an impossibility, rather than the norm. Even the seemingly isolated examples of cultureplaces from the past were perhaps less isolated than we like to imagine. In many cases, there was, most likely, some exchange with others in terms of goods (for example tools) and ideas (such as ways of doing things), as well as people themselves. So while the perceived stability of separate cultureplaces underpins what Welsch (1999) refers to as the "traditional concept of single cultures" (p. 194), this sense of cultures (or cultureplaces if you are willing to accept my argument) as "closed spheres or autonomous islands" (p. 195) is now more of a conceptual problem than a fact, to the extent that it is "untenable today" (p. 195).

The problem Welsch identifies with the 'traditional concept of single cultures' appears to cast a shadow over Peirce's second and first forms of unity when these are applied to understanding culture. Individuality and simplicity seem to highlight "separateness" and "homogeneity" which, Welsch (1999, p. 197) argues, are not adequate ways of conceptualizing cultures today. However there is a way in which these forms of unity can be understood that does not render them as separate and homogeneous. I intend to introduce this way and respond to the issue Welsch raises in the next section, but first I shall engage with Welsch's solution to this issue so as to offer a fuller account of his perspective and to highlight what I believe is a shortcoming. In brief, Welsch contends that, instead of this separateness, cultures have "assumed a new form, which is to be called transcultural insofar as it [culture] passes through classical cultural boundaries" (p. 197). This transcultural form emphasizes a more general cultural mixing, to the extent that the existence of specific cultures (and places) is downplayed or even dismissed.

For Welsch, the notion of 'transcultural' accounts for how "cultural conditions today are largely characterized by mixes and permeations" (1999, p. 197). So instead of living in single cultures we live "transculturally," for "in substance everything is transculturally determined" (p. 198). Consequently, Welsch considers notions normally employed to convey this mixing, such as intercultural and multicultural, to 
fall short of describing how cultures work - because they remain infused with the traditional concept of single cultures. Intercultural refers to the intersections or clashes between cultures, which remain single; for inter- means 'between' and so assumes at least two separate cultures. Hence "the deficiency in this conception ... drags along with it unchanged the premise of the traditional conception of culture. It still proceeds from a conception of cultures as islands or spheres" (p. 196). In the same vein, multicultural denotes a multiplicity of single cultures attempting to live together within the one society. In contrast, "the concept of transculturality aims for a multi-meshed and inclusive, not separatist and exclusive understanding of culture" ( $p$. 200).

It is my observation that this 'multi-meshed and inclusive' transcultural form offers similarities to the way in which nature is considered in human-nature relationships, but from the other side. In human-nature relationships it is nature which subsumes human in a synthesis of ecosystemic relations; nature is 'multi-meshed and inclusive' - as a synthetical form of unity. Correspondingly, transculturality emphasizes what Hannerz (1990) calls a "world culture" which, like nature, is "marked by an organization of diversity rather than by a replication of uniformity" (p. 237). ${ }^{5}$ In effect, means-consequence relations are now being considered more generally as parts of a larger world culture (transcultural) system, just as cause-effect relations are regarded as elements of a natural (biological) system. World culture is a synthetical unity. And like nature there is always diversity within world culture - it is not homogeneous - for such diversity is contained within the total system.

No total homogenization of systems of meaning and expression has occurred, nor does it appear likely that there will be one anytime soon. But the world has become one network of social relationships, and between its different regions there is a flow of meanings as well as of people and goods. (Hannerz 1990, p. 237)

This 'flow of meanings' within 'world culture' is a flow of means-consequence relations involving people, goods and ideas - resultant from learning and resulting in changes. As such, means-consequence relations are not tied to a specific location; they can move by way of specific objects/ideas/people - as mentioned earlier. One obvious outcome is an "increasing interconnectedness of varied local cultures" (Hannerz 1990, p. 237). Another is "the development of cultures without a clear anchorage in any one territory" (p. 237). Here Hannerz seems to suggest that culture can be separated from anchorage in any particular locale. But does this imply that culture can be disconnected from place? Wyse, Nikolajeva, Charlton, Cliff-Hodges, Pointin and Taylor (2012) argue that "globalization ... is a phenomenon that can result in a trivialisation of place" (p. 1020). But is such trivialisation a disconnection? Very important to this question is what we mean by a 'territory' as a specific location. In Hannerz's understanding, territories are "particular areas in physical space" (p. 239), like particular areas on a map or globe - areas which do not move. Yet these immobile physical spaces are not the same as culturally meaningful places. Speaking in connection with outdoor education, Wattchow and Brown (2011) acknowledge that "the relationship between space and place remains one of the most difficult questions facing those interested in studying the human experience of place" (p. 56). I contend that, unlike a fixed territorial space, a place is associated with meaning, with means- 
consequence relations; and means-consequence relations can move, suggesting that place can move with culture: in the unity of cultureplace. ${ }^{6}$

Outdoor education offers many good examples of such movement (although I shall only mention some basic instances here). Outdoor educators tend to conduct particular cultural practices (including activities such as hiking, climbing, skiing, paddling) in ways that embrace certain educational aims (environmental, adventure, etc.). It is worth noting that environmental educational aims may involve quite different means-consequence relations than adventure education aims, suggesting that outdoor education is not a one dimensional form of education when it comes to meanings (see Quay and Seaman, 2013). But apart from consideration of the distinctions developed at the level of aims, what is interesting is that the locations where the relevant cultural practices can occur are not necessarily tied to any single specific territorial space. In other words hiking, climbing, skiing and paddling (whether focused on aims that are environmental or adventure or both) can occur in a range of physical spaces. These different physical spaces (different locations on a map) are not so different, however, when considered in light of the cultural practices occurring there because the same cultural practices can be applied across different spaces, which can thus be considered as like places, such as paddling trips on different flat water rivers. These various rivers are different territorial spaces but not always such different places when the unity of cultureplace is acknowledged especially when these flat water rivers flow through comparable areas of farmland and thus similar landscapes. Similar (but not homogeneous) relations of meansconsequence generally exist across such flat water rivers when on a paddling trip. So while the differences between these spaces may be emphasized such that we notice them, such differences occur on the back of an underlying similarity inherent to place - especially when we consider that on a paddling trip we usually bring in all of our equipment and food, and carry out most of the waste we create. Indeed, as Payne (2002) notes, "culture ... materially and symbolically impregnates the plastic kayaks, carabiners, cambered skis, goretex jackets, geodesic tents, maps/compasses, neoprene wetsuits and kevlar paddles in design, purpose, manufacturing, retailing and, inevitably, use in the outdoor experience and 'penetration' of 'nature"' (p. 17). The point is that culture and place cannot be separated, suggesting a further more agreeable (in light of the current discussion) interpretation of Hannerz's statement that cultures can develop 'without a clear anchorage in any one territory.' This further interpretation highlights how it is cultureplace, not just culture, that may develop without clear anchorage in any one territory.

The possible movement of cultureplaces across space also suggests that one space may be the physical location for many cultureplaces. Flat water rivers may be sites for farming, fishing and birdwatching, just to name a few other cultural practices which may inhabit the same space. And yet this same space means something different in each - it is a different place - because the means-consequence relations are different. In addition, we deliberately change spaces (and places) through design and construction so that they become places where particular cultural practices can readily occur. We make climbing walls and ropes courses, walking trails, ski runs, and even artificial rapids. This has positive and negative ramifications, depending on the educational aims (see Loynes, 1998). 
Hannerz is correct then, when stating that "as collective phenomena cultures are by definition linked primarily to interactions and social relationships, and only indirectly and without logical necessity to particular areas in physical space" (1990, p. 239). For place is not identical with physical space. However Hannerz would be incorrect if he said that cultures are not linked to places. Culture and place are inseparable because the 'interactions and social relationships' of cultures are the result of "conversion" of physical cause-effect relations "into meanings" (Dewey 1929, p. 299). Thus meanings (means-consequence relations) are culturally embedded interpretations of cause-effect relations, situating these relations in cultureplace. Through such conversion of causeeffect relations into means-consequence relations, they are emplaced. A physical space can be separated from social relationships, however a place is identified through the cultural meanings it sustains.

\section{Aesthetic unity and a reworking of the issue of cultureplace boundaries}

When the unity of cultureplace is recognized, it introduces a problem with transculturality, especially as Welsch describes this notion - notably without any mention of place. Welsch (1999) suggests that, once transculturality is acknowledged, then "henceforward there is no longer anything absolutely foreign. Everything is within reach" (p. 198). Such a description of transculturality emphasizes world culture as a phenomenon, but downplays the existence of "sub-cultures ... within the wider whole" (Hannerz 1990, p. 237). The difficulty with sub-cultures is that "while we understand them to be differently located in the social structure of the world, we also realize that the boundaries we draw around them are frequently rather arbitrary" ( $p$. 239). It is these boundaries that seem to be the issue for Welsch. However I aim to show how the unity of cultureplace does not necessarily entail formation of 'closed spheres or autonomous islands' and instead offers a solution to this boundary issue.

Alongside his claims to full cultural access ('nothing absolutely foreign'), Welsch suggests that with transculturality "there is no longer anything exclusively 'own' either. Authenticity has become folklore, it is ownness simulated for others - to whom the indigene himself belongs. To be sure, there is still a regional-culture rhetoric, but it is largely simulatory and aesthetic" (1999, p. 198). Yet this 'ownness' or belonging is what is offered by place, which is not necessarily fixed in space. As I have shown, a 'regional-culture' is not a space-culture but a cultureplace, for "what place literature draws our attention to is the importance of lived experience of place for individual and collective identity" (Wattchow and Brown 2011, p. 66). It is lived experience of place, as cultureplace, that is at the heart of belonging, which often entails a sense of boundary or 'ownness'. But the unity here is not merely synthetical - it is individual/indivisible, and simple - those other forms of unity that Peirce identified. These other forms of unity address the issue of boundaries, but in a very different way than as closed spheres or autonomous islands. In fact, as Welsch acknowledges, these boundaries are 'aesthetic.'

Welsch's description of 'regional-culture' (which I am interpreting contra Welsch as cultureplace rather than space-culture) as 'aesthetic' is actually very helpful, even though he uses this adjective with 'simulatory' to dismiss cultureplace as nothing more than appearance without substance. A deeper sense of aesthetic must be introduced here in order to understand the boundaries at work in culture-place. For 
this again I turn to Dewey (1934, p. 274) and his concept of "[a]esthetic experience." Dewey (1934) considers aesthetic experience to be unified in an emotional sense, for "emotion is the moving and cementing force" in experience, as "it selects what is congruous and dyes what is selected with its color, thereby giving qualitative unity to materials externally disparate and dissimilar. It thus provides unity in and through the varied parts of an experience" (p. 42). Thus "when the unity is of the sort already described [qualitative unity], the experience has [a]esthetic character" (42). In fact Dewey defines "aesthetic unity" as "singleness or congruousness of effect immediately produced through sensuous presentation.” (1902, p. 736).

This aesthetic qualitative unity is a living unity, a unity of living experience 'immediately produced through sensuous presentation'; it is an awareness of the living moment - pure experience. Such unity is aesthetic because it is defined holistically by emotion, by feel. However this does not mean that we can label such unity by merely listing emotions. Such an approach would cast us back into a synthetical unity where emotions are one part of experience amongst others to be connected somehow into a total whole. In contrast to this perspective, Dewey points out that "experience is emotional but there are no separate things called emotions in it" (1934, p. 42). This aesthetic unity is emotional in that it is felt holistically or purely, in the moment. It is the act of feeling the living moment that is central here and we must stay in this act of feeling rather than trying to name it. By feeling this unity we remain in living experience, rather than extracting ourselves from it via a more analytical way of thinking in order to see its parts.

Another feature of this aesthetic unity is that it is simple (Peirce's first form) in that it is not questioned. As we live our lives we are not always questioning the meaning of things around us - we more usually accept these meanings as 'reality'. And for all intents and purposes this unity is 'reality' in this living moment; although as simple unity it is not perceived as a particular cultureplace (meaning that each cultureplace can be defined as a 'reality' in this sense). Lived as simple unity, there is no perception of a boundary. Yet we can also be aware that this cultureplace is one amongst others. As such it is an indivisible individuality (Peirce's second form of unity). Here we are not questioning the parts, the means-consequence relations of a synthetical unity. Rather we are opening up the possibility that this is one indivisible whole amongst others. But in saying this we are not drawing tight boundaries around such wholes; they are not closed spheres or autonomous islands. In a truly living sense these wholes are interpretative and continuously open to change through the flow of meanings, which we call learning. Dewey (1916) captures this in his "technical definition of education: that reconstruction or reorganization of experience which adds to the meaning of experience, and which increases ability to direct the course of subsequent experience" (pp. 89-90). It is meaning which is shifting and changing; evolving.

The distinctions between Peirce's three forms of unity thus offer three different ways of understanding the relation between culture and place. From the perspective of living experience, the aesthetic unity of cultureplace is simple and individual (in the present). Peirce's first form of unity suggests that we live aesthetically, affectively, emotionally, without necessarily being aware that we are involved in one cultureplace amongst others; things just are; their meaning always already inscribed. Peirce's second form of unity instills an awareness of this cultureplace as one amongst others 
- with each cultureplace remaining whole in an aesthetic sense. However, and this is a critical point, this felt whole is not a spatial or cultural boundary. Instead it is a living form, an interpretative whole that is open to change via learning.

Considering culture and place in terms of means-consequence relations as cultureplace invokes Peirce's third form of unity. These relations can be reconstructed or reorganized, as Dewey suggests 'in his technical definition of education,' resulting in change not just to the synthetic unity, but to the aesthetic and individual unity as this is lived - all three forms of unity at the same time (see Quay and Seaman 2016, for an account of experiential learning understood in this way). However when the unity of culture and place is considered a synthetic unity only, then transculturality is a legitimate way to comprehend it, as Welsch suggests. Yet transculturality makes place a problem, as place appears to work against the flows of transculturality because it harnesses culture to a particular region/territory/space. Nevertheless, as I hope I have shown, place is different to space, and cultureplace, as an aesthetic or felt unity, allows for the flow of meanings to occur through learning. Such flow is not boundaryless, as transculturality seems to suggest. The boundaries are of aesthetic experience, acknowledging cultureplace as a unity held in the present moment of pure experience. Thus they are of Peirce's first and second forms of unity, where the whole is primary to a greater extent than in a synthetic unity. It is for this reason that Welsch has difficulty accounting for these boundaries, and why he downplays or dismisses them.

\section{Outdoor education with an awareness of cultureplace unities}

Understanding these three forms of unity has important ramifications for outdoor education. As we attempt to confront issues of human-nature relationships through our educational practices, we must be aware that there is more to comprehending these relationships than perhaps initially meets the eye. Stewart (2004) attests to the need for a deeper understanding, arguing that "the relatively recent quest in outdoor education to 'develop human-nature relationships' or "connect with nature" is "a cause for concern" (p. 47). For "while the idea is commendable, without consideration or acknowledgement of the place, culture, context or situation of an experience it could be argued that this is another form of colonialism, or neocolonialism perhaps" (p. 47). Stewart's statement highlights the deeper level of experiential nuance achievable via cultureplace and culture-place when contrasted with human-nature. Here is an awareness that cultureplace is a unity formed aesthetically as well as meaningfully. However this does not preclude one cultureplace from competing with another in terms of the ways in which a particular physical location may be understood and lived with.

With acknowledgment of the movement of cultureplace, it is eminently predictable that these various lived aesthetic unities of experience will come into conflict as they seek to inhabit the same physical space. Such conflict can be understood in the form of cultural and environmental crises, highlighted by McKenzie at the beginning of this paper. The notion of cultureplace unity suggests that cultural crises and environmental crises are one and the same, seen from different vantage points - one view emphasizing culture and one place, where place is an interpretation of environment. Awareness of the aesthetic character of the boundaries between cultureplaces and the ways in which these aesthetic boundaries can be shifted and changed through learning 
by addressing means-consequence relations and their varying interpretations illuminates an educational pathway through the conflicts that ensue between cultureplaces.

This does not mean that one cultureplace must necessarily triumph over the other(s) holus bolus, but that specific meanings are brought into question. This then opens up awareness of the synthetical unity of culture-place, suggesting that, as Dewey highlights, we can reconstruct and reorganize means-consequence relations, thus adding to the meaning of experience, and increasing our ability to successfully direct further experience. This is a key aspect of how a deeper sense of learning may work, one which is evident in much outdoor education. Not just as learning/adapting to a particular cultureplace, but as recognition of the complexities that accrue to encounters between different cultureplaces. These can be as basic as those living moments during an outdoor education trip where decisions have to be made by the group as to which route to take - the shorter more efficient option or the longer more scenic option - for each offers a subtly but powerfully different version of cultureplace. Or they can be as complex as the confrontations between different 'users' of national parks - the four wheel drive enthusiast and the hiker - for each, again, lives a different cultureplace.

Outdoor education is well positioned to confront these encounters educationally, especially considering that they can be partially planned for through the ways in which programs are arranged - to arise in moments of living experience. Planning for and working through such confrontations educationally will hopefully benefit from the argument offered in this paper, leading to practices that may better enable us to educationally address the many issues of cultureplace that challenge us today.

\section{Acknowledgments}

Included in cover letter

\section{Notes}

1. Outdoor education can be interpreted very broadly. For discussion of the historical development of this form of education, at least in the USA, see Quay and Seaman (2013).

2. The importance of language, as logos, to this shift is made clear by Dewey when speaking of communication (1929, pp. 138-140).

3. "Always already" is a Heideggerian (2010/1927, p. 169) expression aimed at conveying the temporal sense of the living present as unquestioned simplicity (Peirce's first form of unity).

4. A lack of change may mask political machinations that support maintenance of traditions. An interesting short story that explores this idea is Theodor Storm's (1888) Der Schimmelreiter, translated into English as The Dykemaster.

5. Welsch $(1999$, pp. 205, 208) refers to the work of Hannerz (1990) in connection with transculturality but he does not specifically draw on the concept of world culture. 6. I also suggest that cultureplace and culture-place can be aligned with Dewey's (1916) notion of “occupations" (p. 361). 


\section{References}

Dewey, J. 1900. The school and society. New York: McClure, Phillips and Co.

Dewey, J. 1902. Unity. In J. M. Baldwin, ed. Dictionary of philosophy and psychology, Vol. II. 736. New York: Macmillan.

Dewey, J. 1916. Democracy and education. New York: The Free Press.

Dewey, J. 1929. Experience and nature. 2nd ed.. Chicago: Open Court Publishing Company.

Dewey, J. 1931. Social science and social control. New Republic 67 (Jul 29), 276277.

Dewey, J. 1933. How we think: A restatement of the relation of reflective thinking to the educative process. rev. edn. Boston: D. C. Heath and Company.

Dewey, J. 1934. Art as experience. New York: Capricorn Books.

Dewey, J. 1936. General propositions, kinds and classes. The Journal of Philosophy 33 (25), 673-680.

Dewey, J. 1937. Charles Sanders Peirce. New Republic 89 (February 3), 415-416.

Dewey, J. 1938. Experience and education. New York: Collier Books.

Hannerz, U. 1990. Cosmopolitans and locals in world culture. Theory, Culture and Society 72, 237-251.

Heidegger, M. 2010/1927. Being and time. rev. trans. J. Stambaugh, Trans. Albany: State University of New York Press.

James, W. 1912. Essays in radical empiricism. London: Longmans, Green and Co.

Loynes, C. 1998. Adventure in a bun. The Journal of Experiential Education 21 (1), 35-39.

Martin, P. 2004. Outdoor adventure in promoting relationships with nature. Australian Journal of Outdoor Education 8 (1), 20-28.

Martin, P., and G. Thomas. 2000. Interpersonal relationships as a metaphor for human-nature relationships. Australian Journal of Outdoor Education 51, 39-46.

McKenzie, M. 2008. The places of pedagogy: Or, what can we do with culture through intersubjective experiences. Environmental Education Research 143, 361373.

Quay, J. 2003. Experience and participation: Relating theories of learning. Journal of Experiential Education 26(2), 105-112. 
Quay, J., and J. Seaman, J. 2013. John Dewey and education outdoors: Making sense of the 'educational situation' through more than a century of progressive reforms. Rotterdam, NL: Sense Publishers.

Quay, J., and J. Seaman. 2016. Outdoor studies and a sound philosophy of experience. In B. Humberstone, H. Prince, and K. A. Henderson eds., Routledge International Handbook of Outdoor Studies. 40-48. London: Routledge.

Payne, P. 2002. On the construction, deconstruction and reconstruction of experience in 'critical' outdoor education. Australian Journal of Outdoor Education 62, 4-21.

Peirce, C. S. 1902. Unity. In J. M. Baldwin ed., Dictionary of philosophy and psychology, Vol. II. 734-736. New York: Macmillan.

Salmón, E. 2000. Kincentric ecology: Indigenous perceptions of the human-nature relationship. Ecological Applications 10 (5), 1327-1332.

Stewart, A. 2004. Decolonising encounters with the Murray River: building place responsive outdoor education. Australian Journal of Outdoor Education 8 (2), 46-55.

Thayer-Bacon, B. J. 2003. Relational “(e)pistemologies.” New York: Peter Lang Publishing.

Wattchow, B., and M. Brown. 2011. A pedagogy of place: Outdoor education for a changing world. Clayton, AUS: Monash University Publishing.

Welsch, W. 1999. Transculturality: the puzzling form of cultures today. In M. Featherstone and S. Lash, eds. Spaces of culture: City, nation, world. 194-213. London: Sage.

Wyse, D., M. Nikolajeva, E. Charlton, G. Cliff-Hodges, P. Pointin, and L. Taylor. 2012. Place-related identity, texts, and transcultural meanings. British Educational Research Journal 38 (6), 1019-1039. 


\section{University Library}

\section{- M M N E R VA A gateway to Melbourne's research publications}

Minerva Access is the Institutional Repository of The University of Melbourne

Author/s:

Quay, J

Title:

From Human-Nature to Cultureplace in Education Via an Exploration of Unity and Relation in the Work of Peirce and Dewey

Date:

2017-07-01

Citation:

Quay, J. (2017). From Human-Nature to Cultureplace in Education Via an Exploration of Unity and Relation in the Work of Peirce and Dewey. STUDIES IN PHILOSOPHY AND EDUCATION, 36 (4), pp.463-476. https://doi.org/10.1007/s11217-016-9507-6.

Persistent Link:

http://hdl.handle.net/11343/283034 